\title{
Digital Algal Cell Growth Analysis and Time Determination of Pediastrum sp using Fuzzy Inference System
}

\author{
Sabeeha Sultana \\ Asst. Professor \\ PESIT University \\ Bangalore-560100
}

\author{
Gowri Srinivasa, PhD \\ Professor \\ PESIT University \\ Bangalore-560100
}

\author{
N. Thajuddin, PhD \\ Professor/HOD \\ Bharatidasan \\ University,Tamilnadu
}

\begin{abstract}
The main aim of the present study is to develop an automatic tool to identify and classify the growth stage of the microalgae cell based on morphological growth pattern and also the division time of the individual cell of microalgae population. The proposed strategy is to capture digital images of the microalgae cell growing on culture media and to examine the change in dimensions of each cell throughout the life cycle. To identify geometrical features that are used in estimating the microalgae cell properties, which are helpful for time determination during cell division. The Segmentation method used here is Active Contour and classification is done using fuzzy inference system and decision trees. The experimental results are compared with manual results obtained by phycologist and demonstrate the efficiency of the system.
\end{abstract}

\section{Keywords}

Cyanobacteria, algae, growth phases, cell segmentation, fuzzy inference system

\section{INTRODUCTION}

According to autecological studies, microalgae morphological growth in culture exhibits five different growth phases namely, lag phase, log phase, exponential phase, stationary phase, and death phase. During the time interval of lag phase, the algal cell will adapt themselves to growth conditions. This is the phase where individual algae cell is matured but not yet able to divide. During log phase and Exponential phase, this is a period which is characterized by cell doubling. The number of new algal cell appearing per unit of time is proportional to the present population. On account of rapid depreciation of nutrients and accumulation of toxic, the Exponential phase cannot continue indefinitely. During stationary phase, the growth rate slows as a result of nutrient depletion in the culture media. This phase exhibits constant value as the rate of algal growth is equal to the rate of algal cell death. The last phase is death phase, algae run out of nutrients and die [1]. The generation time is important in determining the amount of chlorophyll a, b, carotenoid, proteins, biomass during the different morphological growth phases. The algae cell growth cycle is shown in Fig 1.

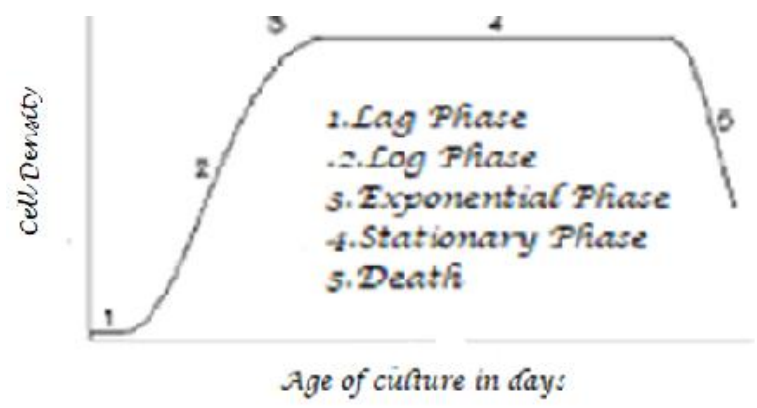

Fig 1: Algal growth phases during the life cycle

For our experimentation, the microalgae cell images are captured at regular intervals in terms of days that are for cell division time determination. Form the literature survey it is evident the growth and the changes in an individual cell by image analysis using statistical analysis was investigated by A.Elfwing et al[2]. Influence of environmental stress on distributions of times to first division in Escherichia coli populations is determined by using digital image analysis of individual cells. A analysis method for measuring lag times in division of individual bacterial cells using image analysis based on geometrical features has been done by Gorden W.Niven et al[3] . Experimental study of cell shape and division in Escherichia coli has been carried out by Kenneth $\mathrm{J}$ Begg. [4]. Automated identification and classification of bacilli bacterial cell growth phases based on geometric features by Hiremath and Parashuram[5]

The characteristics that need to be considered and studied in the present work are the size of the cells before and after division, the variation in the generation time of algal cells, spatial and successive change in morphology of the individual cell size. The factors that play a vital role in changes in morphological growth phases during the life cycle of microalgae are temperature, light, $\mathrm{pH}$, and medium components. By change in any of the above factor shows the changes in the morphological patterns of the cell in each of the growth phases.

\section{MATERIALS AND METHODS}

This present study was performed on Pediastrum sp, a green alga predominant in freshwater. These Pediastrum $s p$ colonies are commonly found in the form of a colony, disk-shaped and are characterized by peripheral hornlike projections. Depending on the species the cells present per colony varies. These samples are collected from department of microbiology Bharathidasan university, Tamilnadu. These species are studied under a Phase contrast microscope attached with a 
camera. Cultures were grown in $\mathrm{BG}-11+\mathrm{N}$ medium for 30 days at an optimal temperature of $25{ }^{\circ} \mathrm{C}$, and $\mathrm{pH}$ of 7 with dark and light cycles (16: 8) under illumination of 2400 LUX.

\section{PROPOSED SYSTEM}

\subsection{Active Contour}

An active contour is essentially a curve made up of various energies. The curve deforms dynamically to the shape of a targeted object. There are various methods for implementing an algorithm to achieve object outlining. The energies in the active contour can be divided into two categories. Internal and External energy functions which have the relationship are discussed. The Internal energy functions focus on the intrinsic properties of the contour such as elasticity and curvature, while the external energy functions are related to the image properties like contrast and brightness.

\section{Esnake $=$ Einternal + Eexternal}

Active contours are curves that move within images to find object boundaries. They are often used to detect and locate objects in computer vision and image analysis and even for describe their shape. For example, a snake might be used edge detection, corner detection, motion tracking, and stereo matching; one might be used to find the outline of an organ in a medical image, or one might be used to automatically identify characters on a postal letter. Snake is active contour models: they lock onto nearby edges, localizing them accurately. Scale-space continuation can be used to enlarge the capture region surrounding a feature. The external constraint forces are responsible for putting the snake near the desired local minimum. These forces can, for example, come from a user interface, automatic attentional mechanisms, or high-level interpretations. Representing the position of a snake parametrically by $\mathrm{v}(\mathrm{s})=(\mathrm{x}(\mathrm{s}), \mathrm{y}(\mathrm{s}))$, To obtain the best fit between the snake and the object, we minimize the energy. Specifically, a snake is defined as

$$
\begin{aligned}
\mathrm{E}_{\text {snake }}^{*} & =\int_{0}^{1} E_{\text {snake }}(v(s)) d s \\
& =\int_{0}^{1} E_{\text {int }}(v(s)) d s+\int_{0}^{1} E_{\text {image }}(v(s)) d s+\int_{0}^{1} E_{\text {forces }}(v(s)) d s
\end{aligned}
$$

Where internal energy of the spline due to bending, gives rise to the image forces, and gives rise to the external constraint forces.

The internal energy provides a smoothness constraint. This can be further defined as

$$
E_{\mathrm{int}}=\alpha(s)\left|\frac{d v}{d s}\right|^{2}+\beta(s)\left|\frac{d^{2} v}{d^{2} s}\right|^{2}
$$

The spline energy is composed of a first-order term controlled by $\alpha(\mathrm{s})$ and a second-order term controlled by $\beta(\mathrm{s})$. Adjusting the weights $\alpha(\mathrm{s})$ and $\beta(\mathrm{s})$ controls the relative importance of the membrane and thin-plate terms. The external energy function:

$$
\beta E_{\theta u t}\left(u_{i}\right)=m E_{m a g}\left(u_{i}\right)+g E_{g r a d}\left(u_{i}\right)
$$

where $E_{\text {mag }}\left(\nu_{\mathbf{i}}\right)_{\text {is an }}$ expression that attracts the contour to high or low-intensity regions and $E_{\text {grad }}\left(v_{i}\right)$ is an energy term that moves the contour towards edges? Again, the constants, $\boldsymbol{m a n d} \boldsymbol{g}$, are provided to adjust the relative weights of the terms. The total image energy can be expressed as a weighted combination of the three energy functional.

$$
E_{\text {image }}=\omega_{\text {line }} E_{\text {line }}+\omega_{\text {edge }} E_{\text {edge }}+\omega_{\text {term }} E_{\text {term }}
$$

The present study is developed to automate a method to determine the different cell growth morphology during different phases in the life cycle of cyanobacteria and also to know the time of individual cell of an algal population. Based on determining geometrical feature and statistical features. The geometrical feature considered for this experimental study are length, breadth, area, perimeter, Circularity, Entropy and box area ratio(BAR) which are defined as:

Length: longer or longest dimension of an object under consideration

Breadth: breadth is used to describe the distance from the right side to the left side of a shape

\subsection{Training and Classification}

The proposed study to detect and identify different morphological stages of an algal image and also time determination of algal cells captured at regular intervals (in terms of the number of days) based on their geometrical and statistical features values.

\subsubsection{Algorithm}

During training phase (Segmentation and feature extraction of cell regions)

1. Input an algal digital cell image

2. Preprocesses the image by using morphological operations like filling, erosion, dilution, an area open.

3. Segment the input digital image using Active Contour or snake.

4. Label the segmented image, where the individual segment is known as cell region.

5. For each of segmented cell in an image compute the BAR value and area, perimeter, circularity, eccentricity, centroid

6. Repeat the above procedure from 1 to 5 for all cell images taken on a regular interval in terms of the number of days namely $1,3,5,7$, so on 30 th day and store them as the knowledge base.

\subsubsection{Algorithm: Classification phase}

1. Input an algal digital cell image

2. Preprocesses the image by using morphological operations like filling, erosion, dilution, the area open.

3. Segment the input digital image using Active Contour or snake.

4. Label the segmented image, where an individual segment is known as cell region.

5. For each of segmented cell in an image compute the BAR value and area, perimeter, circularity, Entropy

6. Repeat the above procedure from 1 to 5 for all cell images taken on the regular interval in terms of the number of days and store them as the knowledge base. 
7. Apply the decision rules, for all test cell images captured at regular number of days for determination of the cell growth phases, namely, Lag, log, Exponential and stationary and death phases cell division times corresponding to initial division, second division, etc., based on the values obtained from Area computed with respect to each segmented cell in an image for different phases. Decision Rules

\subsection{Decision Rules}

The decision rules for the classification algorithm is obtained from section 3.1 by taking the training data set:

1. Based on the cell division time in the lag phase, say if the value of the Area of each cell is in between 4000 and 4700 then that cell belongs to lag growth phase it is a normal cell.

2. If the Area value of the cells is 4800 and 5800 then this particular cell is in the lag phase but it is in about-to-divide (grown up) stage

3. If the Area value of the individual cell varies in between 6000 to 37500 then the cell is in a log or in the exponential stage. Which indicate that the single cell has undergone division.

4. If the Area value of the individual cell varies in between 40000 to 57000 then the cell is in stationary phase and the cell division time is (25 to $30^{\text {th }}$ day).

The above decision values are summarized in the decision table given in Table1. This table contains the information about a different range of Area values at a given time interval in term of the number of days, which corresponds to different morphological growth phases obtained from training images and stored in the knowledge base. These above rules that are present are helpful in the fuzzy inference rules for the classification system.

Table 1: Decision rules to determine morphological growth phases during the life cycle of Pediastrum $s p$

\begin{tabular}{|c|c|c|c|}
\hline \multicolumn{2}{|c|}{ Inputs } & \multicolumn{2}{c|}{ Decision } \\
\hline $\begin{array}{l}\text { Range of Area } \\
\text { values }\end{array}$ & $\begin{array}{l}\text { Time of division in terms of } \\
\text { Days(approx.) }\end{array}$ & Cell Growth Phases & Cell division determination \\
\hline 4000 to 4700 & $1-3$ & Lag Phase & Grown Up \\
\hline 4800 to 5800 & $4-7$ & Lag Phase & First division \\
\hline 6000 to 37500 & $8-22$ & Stationary Phase & Second division \\
\hline 40000 to 57000 & $22-29$ & Stationary phase & Final division \\
\hline 57000 to 58000 & $29-32$ & & \\
\hline
\end{tabular}

\section{EXPERIMENT RESULTS AND DISCUSSION}

In the present study, we have considered Pediastrum $s p$ cyanobacteria cell images which exhibit different growth phases based on morphology chaptered.300 sample is considered to carry out the experiment. The image is size is of 350x350. The dataset contains 90,80, and 70 images corresponding to lag, log/exponential, and stationary phases. Among the entire data set $50 \%$ is chosen as training set and remaining 50\% as the testing dataset from Fig 2. It is observed that the sample of Pediastrum sp cell images captured and shows different morphology in growth patterns and subsequently the corresponding segmented images is shown in Fig 3. It is observed that the first division of Pediastrum $s p$ on BG-11 at $25+\_2{ }^{\circ} \mathrm{C}$, after a duration of 3 days the cells of this species in normal stage. This is a lag phase as shown in Table 1. After this the normal cell began to grow and get divided, this indicates the cell is moving from lag phase to log/exponential phase the time taken to attended this phase is approx. from the fifth day to $21^{\text {st }}$ day depending on species under consideration Pediastrum sp. these cells again increase in their dimension multiples at a faster rate. When the cell entire in the third phase i.e. stationary phase it stops dividing and remain in the same state and then later as the nutrients in the medium degraded the cell slowly moves towards the death stage.

\subsection{Fuzzy Inference Classification System}

Another powerful area for decision making is fuzzy logic [6]. In fuzzy logic and fussy sets, fuzzy inference system is one of the most well-known applications [7]. The FIS contains many fuzzy rules that are designed by experts. These expert's system is based on classical Boolean system. Mamdani was the first person to propose a FIS [8]. There are few parameter designs associated with this method such as membership functions and designing rules. Various authors have shown various advantages and drawbacks [9-10].

Computing the mean and standard deviation of the training dataset. The Mamdani is used to model any inference system in which membership function is either linear or constant [11]. The fuzzy membership functions for Area corresponding to a lab, log/exponential, and stationary phases are shown in Fig 5. where the lag phase is divided as early and late lag phase, then followed by log/exponential phase and stationary phase. Mean and Standard deviation of Area values computed for an individual cell captured at regular intervals w.r.t days is shown in Table 2. Classification accuracy of the proposed method for Pediastrum sp cyanobacterial morphological cell growth phases is as shown in Table 3. And also, confusion matrix is plotted for cell growth phases of Pediastrum $s p$ during its life cycle in Table 4. 

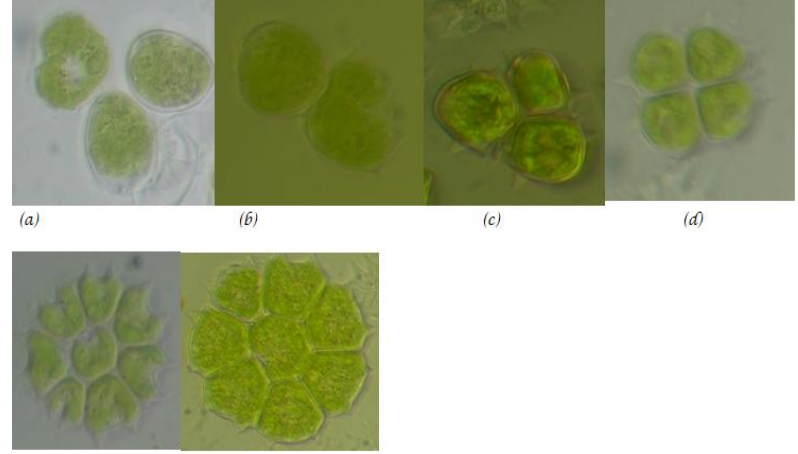

(e) (f)

Fig 2 :(a \& b) Lag Phase (c)Log Phase (d \& e) Exponential phase(f)Stationary phase

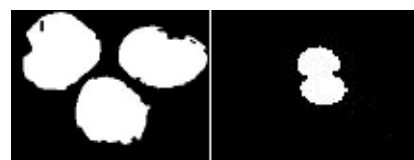

(a)

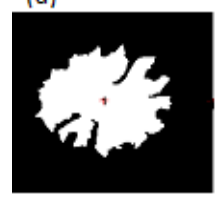

(e)

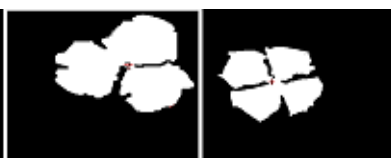

(d) (b)

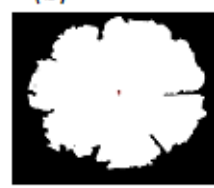

(f)
Fig 3: Segmented images of Pediastrum sp (a \& b) Lag Phase (c)Log phase (d \&e) Exponential phase (f) Stationary phase.

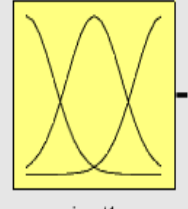

input1

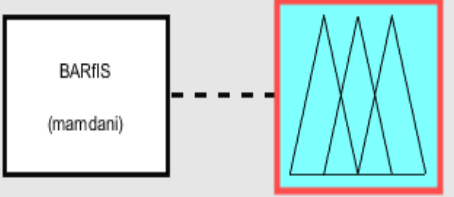

output1
Fig 4: Fuzzy Inference system model

Computing the mean and standard deviation of the training dataset. The Mamdani model is used to model any inference system in which membership function is either linear or constant [11]. The algal growth curve shown in Fig 5 shows the increase in area at each growth phase during the life cycle. The fuzzy membership functions for Area corresponding to lag, log/exponential and stationary phases are shown in Fig 6. where the lag phase is divided as early and late lag phase, then followed by log/exponential phase and stationary phase. Mean and Standard deviation of Area values computed for an individual cell captured at regular intervals w.r.t days is shown in Table 2.
Table 2: Categorization of growth phases with a description of cell area in each phase

\begin{tabular}{|l|l|l|l|l|}
\hline & Lag Phase & \multicolumn{1}{|c|}{ Log } & \multicolumn{1}{|c|}{$\begin{array}{c}\text { Exponential } \\
\text { phase }\end{array}$} & $\begin{array}{c}\text { Stationary } \\
\text { Phase }\end{array}$ \\
\hline Time & 0 to 3 days & $\begin{array}{c}4 \text { to } \\
10\end{array}$ & 15 to 21 & 21 to 30 \\
\hline $\begin{array}{l}\text { Average } \\
\text { cell area }\end{array}$ & $1.36+0.764$ & $\begin{array}{l}1.446+- \\
0.601\end{array}$ & $\begin{array}{l}1.686+- \\
0.878\end{array}$ & $\begin{array}{l}1.856+- \\
0.124\end{array}$ \\
\hline
\end{tabular}

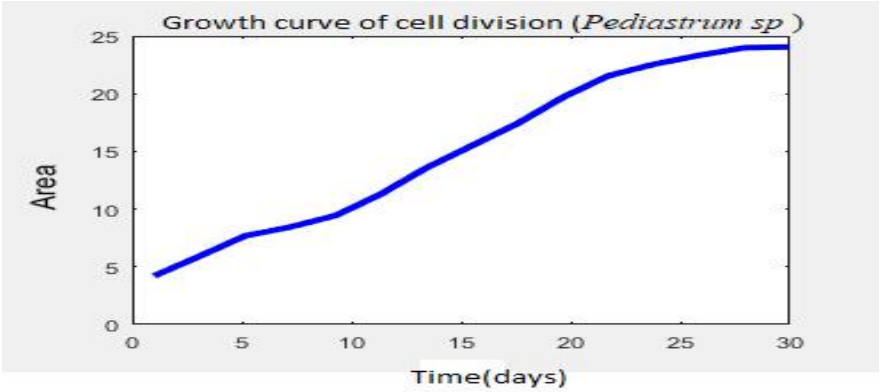

Fig 5: Area of different phases during the life cycle

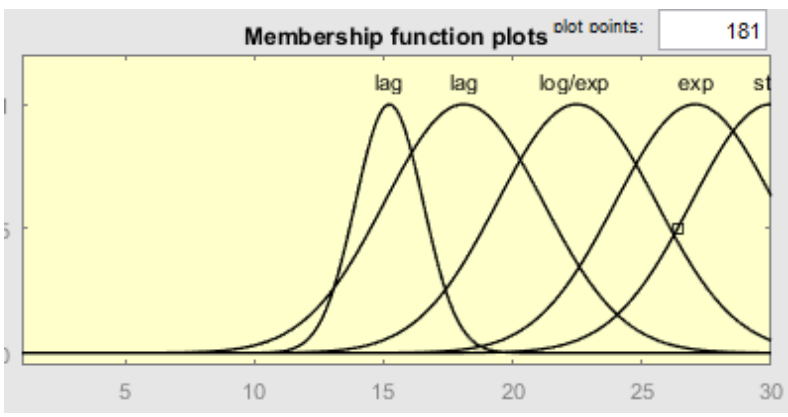

Fig 6: Membership functions related to lag, log/exponential and stationary phase.

Table 4: Confusion matrix for classification of cell growth rate of Pediastrum sp

\begin{tabular}{|l|c|c|c|c|}
\hline $\begin{array}{l}\text { Confusion } \\
\text { Matrix }\end{array}$ & $\begin{array}{l}\text { Initial } \\
\text { stage }\end{array}$ & $\begin{array}{l}\text { Second } \\
\text { stage }\end{array}$ & $\begin{array}{l}\text { Third } \\
\text { stage }\end{array}$ & $\begin{array}{l}\text { Final } \\
\text { growth } \\
\text { phase }\end{array}$ \\
\hline Initial stage & 296 & 4 & 0 & 0 \\
\hline $\begin{array}{l}\text { Second } \\
\text { stage }\end{array}$ & 1 & 298 & 1 & 0 \\
\hline Third stage & 0 & 0 & 294 & 6 \\
\hline $\begin{array}{l}\text { Final } \\
\text { growth }\end{array}$ & 0 & 0 & 1 & 299 \\
\hline
\end{tabular}

\section{CONCLUSION}

In the present study an automated model to identify and classify morphological algae growth phases and individual cell division time during a life cycle is proposed using fuzzy inference system. The geometric feature values of segmented cell are used for cell division time determination. The Pediastrum $s p$ images are captured at regular interval in terms 
of days and experiment is set up based on these images. The present system uses fuzzy inference system which yields a comparable classification rate which ranges in between $90 \%$ $100 \%$ for each cell growth phase. As the species under study produces lipids by this study it will help in analyzing in which phase of morphology growth phases of the species the amount of lipids produced.

\section{REFERENCES}

[1] Pommerville, J.C.: Alcamo's Fundamentals of Microbiology Body systems edition. Jones and Bartlett Publishers (2010)

[2] Elfwing, A., LeMarc, Y., Baranyi, J., Ballagi, A.: Observing Growth and Division of Large Numbers of Individual Bacteria by Image Analysis. Applied and Environmental Microbiology 70(2), 675-678 (2004)

[3] Niven, G.W., Fuks, T., Morton, J.S., Mackey, B.M: Influence of Environmental Stress on Distributions of Times to First Division in Escherichia coli Populations, as Determined by Digital-Image Analysis of Individual Cells. Appl. Environ. Microbiol. 74(12), 3757-3763 (2008)

[4] Begg, K.J., Donachie, W.D.: Division Planes Alternate in Spherical Cells of Escherichia coli. Journal of Bacteriology 180(9), 2564-2567 (1998)
[5] Hiremath, P.S., Bannigidad, P.: Automated identification and Classification of Bacilli Bacterial Cell Growth Phases. IJCA Special Issue on Recent Trends in Image Processing and Pattern Recognition (RTIPPR2010) 1(2), 48-52 (2010).

[6] L. A. Zadeh, "Fuzzy sets," Inform. Control, vol. 8, pp. 338-353, 1965.

[7] E. H. Mamdani and S. Assilian, "An experiment in linguistic synthesis with a fuzzy logic controller," Int. J. Man-Mach. Stud., vol. 7, pp. 1-13, 1975.

[8] T. Takagi and M. Sugeno, "Fuzzy identification of systems and its applications to modeling and control," IEEE Tran. Syst., Man, Cybern., vol. SMC 15, pp. 116$132,1985$.

[9] J.-S. R. Jang, C.-T. Sun, and E. Mizutani, Neuro-Fuzzy and Soft Computing. Englewood Cliffs, NJ: Prentice Hall, 1997.

[10] P.Y.Glorennec,Algorithmesd'apprentissagepoursystèmes d'inférence floue. Paris, France: Hermès, 1999.

[11] Sivanandam, S.N., Sumathi, S., Deepa, S.N.: Introduction to fuzzy logic using MATLAB. Springer, Hiedelberg (2007). 